\title{
Trends in and correlates of use of roll-your-own cigarettes: a population study in England 2008-2017
}

\author{
Sarah E. Jackson ${ }^{1}$, Lion Shahab ${ }^{1}$, Claire Garnett ${ }^{1}$, Jamie Brown ${ }^{1,2}$ \\ ${ }^{1}$ Department of Behavioural Science and Health, University College London, London, UK \\ ${ }^{2}$ Department of Clinical, Educational and Health Psychology, University College London, UK
}

Key words: roll-your-own; hand-rolled tobacco; cigarette smoking; population survey

Word count: 3,623

Corresponding author: Sarah E Jackson, PhD. Department of Behavioural Science and Health, University College London, 1-19 Torrington Place, London WC1E 6BT

Tel: (44) 2076793179

Fax: (44) 2079168354

s.e.jackson@ucl.ac.uk 


\section{Abstract}

Introduction: Understanding the use of cheaper roll-your-own cigarettes may have implications for tobacco tax policy. We examined trends in RYO cigarette use in England between 2008 and 2017, and characterised users' sociodemographic and smoking profiles.

Methods: We used data from 211,469 respondents to a survey representative of the adult ( $\geq 16 y)$ population. In current smokers across the entire study period $(n=43,389)$, we assessed multivariable associations between cigarette type (RYO/FM) and sociodemographic and smoking characteristics. Among current smokers in 2008 and $2017(n=7,685)$, we tested interactions between year and cigarette type to assess the stability of each characteristic.

Results: Between 2008 and 2017, FM cigarette use declined from 15.3\% to 9.2\% while RYO use increased from $6.7 \%$ to $8.1 \%$. Greater odds of RYO use were observed among younger, male smokers from lower social grades, who were more addicted and used e-cigarettes $\left(\mathrm{OR}_{\mathrm{range}}=1.28-1.86, p<0.001\right)$. Lower odds of RYO use were observed among non-daily smokers, those with high motivation to stop, and higher spending on smoking $\left(\mathrm{OR}_{\text {range }}=0.46-0.89, p \leq 0.001\right)$. The RYO smoker profile was relatively stable between 2008 and 2017. However, compared with FM use, RYO use increased in younger $(p<0.001)$ and female $(p=0.019)$ smokers, and there was a relatively smaller decline in the proportion cutting down or trying to quit $(p=0.004)$.

Conclusion: In England, RYO use increased when overall smoking prevalence and FM use decreased. The profile of RYO smokers remained relatively stable, with users typically younger, male, more addicted, deprived, spending less on smoking, and less inclined to quit than FM smokers.

Implications: This population-based study provides novel insight into recent trends in RYO use in England, providing an up-to-date understanding of the profile of RYO smokers in England. Without the consistent application of tax across the range of combustible products, smokers who are more dependent are able to capitalise on the lower cost of RYO in order to continue smoking, undermining the potential benefit of taxation on cessation. 


\section{Introduction}

Reducing smoking prevalence remains a public health priority [1]. Increasing the price of cigarettes via taxation can reduce smoking uptake and promote cessation [2-7]. However, its impact may be mitigated by smokers using cheaper brands or roll-your-own (RYO) cigarettes. In England, RYO cigarettes cost around half the price of factory-made (FM) cigarettes, primarily because they are subject to a lower level of taxation [8]. The lower cost means individuals who use RYO cigarettes are significantly less likely to try to quit [9]. A prerequisite to policy action is an up-to-date understanding of the profile of RYO users in England. This study reports the sociodemographic and smoking characteristics of smokers who use RYO cigarettes in England, and how these have changed over time relative to smokers who use FM cigarettes.

Evidence indicates that in contrast to the declines in overall smoking prevalence and consumption of FM cigarettes that have occurred in the UK over recent decades, use of RYO cigarettes has increased [10-14]. Data from the General Lifestyle Survey indicate that between 1974 and 2010, the prevalence of smoking fell by more than half, from $45 \%$ to $20 \%$ [14]. However, the proportion of smokers using RYO cigarettes increased considerably, from $13 \%$ to $39 \%$ in men and from $1 \%$ to $23 \%$ in women [14]. Similar trends for increasing use of RYO cigarettes in the context of declining prevalence of smoking have been observed in the UK International Tobacco Control (ITC) Project, a longitudinal survey of 2,000 smokers [11-13], although the most recent data published indicated that the prevalence of RYO cigarette use levelled off between 2010 and 2014 [13].

While RYO cigarettes are growing in popularity, they have not been adopted uniformly across socioeconomic groups. In the UK ITC survey, RYO use was associated with younger age, male sex, lower level of education, lower annual income, financial stress, heavier smoking, higher level of nicotine addiction, and lower motivation to stop $[11,12,15]$. Additional associations with white ethnicity, routine/manual occupations, unemployment and region (higher prevalence in south west England and Wales, compared with London) have been identified in the General Household Survey [10]. This raises the possibility that the lower cost of RYO has increased health inequalities in the UK.

To our knowledge, no data on trends in prevalence of RYO use have been reported beyond 2014; and the most recent comprehensive assessment of sociodemographic and smoking-related correlates of RYO use was conducted on data collected between 2002 and 2008 [11]. This literature needs updating for several reasons. First, previous work has shown substantial changes in prevalence of RYO use over relatively short 
time periods, for example from $26.4 \%$ of smokers in 2007 to $32.7 \%$ in 2010 [12]. The UK ITC survey data indicate a possible plateau in RYO usage between 2010 and 2014 but the authors note that no data were available for 2011 or 2012 so fluctuations during this period were not examined. It is plausible that current prevalence of RYO use may differ from the most recent available estimate, and nuanced trends in usage since 2010 may not have been accurately reflected by existing literature.

Secondly, changes to tobacco control policy are likely to have had an effect on RYO usage. Importantly, the 2016 budget included measures to tackle cheap tobacco, including an increased 3\% duty on RYO tobacco [1], reducing the tax differential between RYO and FM cigarettes in the UK. With a majority of smokers who use RYO cigarettes citing cost as a central factor driving their choice of tobacco product [11,12], such a change in taxation policy may have reduced motivation to swap from more expensive products to RYO, causing the rate of increase in prevalence of RYO usage to slow.

Finally, changes in the economic climate over the last decade may have altered the profile of RYO users, with the recession of 2008/09 necessitating a switch from more expensive premium tobacco products to cheaper alternatives. Although studies conducted before the global financial crisis demonstrated associations between use of RYO cigarettes and socioeconomic disadvantage $[10,11,15]$, increasing financial difficulties may have amplified the disparity in usage between socioeconomic groups.

Using data from a large sample representative of the adult population in England, collected between January 2008 and December 2017 (inclusive), this study aimed to provide insights into recent trends in RYO cigarette use in England, and characterise users in terms of their sociodemographic and smoking profiles. Specifically, we aimed to answer the following research questions:

1. To what extent has the use of RYO cigarettes relative to FM cigarettes in England changed between 2008 and 2017?

2. How do current smokers of RYO cigarettes differ from FM cigarette smokers in sociodemographic and smoking characteristics across the entire study period?

3. To what extent do differences in smoking-related characteristics between current RYO cigarette smokers and FM cigarette smokers persist after adjustment for sociodemographic characteristics?

4. Has the sociodemographic/smoking profile of current RYO cigarette smokers changed between 2008 and 2017 and, if so, in what way? 


\section{Method}

\section{Study population}

The Smoking Toolkit Study is an ongoing cross-sectional survey with a different representative sample of adults in England each month designed to provide insights into population-wide influences on smoking and cessation by monitoring trends on a range of variables relating to smoking [16]. The study uses a hybrid random location and quota sampling to select a new sample of $\sim 1,700$ adults ( $\geq 16 y$ ) each month. Participants complete a face-to-face computer-assisted survey with a trained interviewer. Comparisons with national data indicate that key variables including sociodemographics and smoking prevalence are nationally representative [16].

The present study used aggregated data from respondents in the period from 2008 to 2017 (the most recent full year of available data).

\section{Measures}

Participants who reported smoking cigarettes (FM or RYO) daily or occasionally were asked to report the number of cigarettes they smoked on an average day, and how many were RYO. For the purpose of the present analyses, we examined any use of RYO cigarettes (defined as $>0 \%$ of total cigarette consumption), predominant use ( $\geq 50 \%$ of total cigarette consumption; a definition used by other studies examining RYO cigarette usage [11]) and exclusive use (100\% of total cigarette consumption).

Sociodemographic characteristics assessed were: age, sex, social grade (an occupational index of socioeconomic position, categorised as $A B C 1$, which includes managerial, administrative and professional and occupations, vs. C2DE, which includes semi-routine and routine occupations, manual occupations, never workers and long-term unemployed [17]) and region (Government Office Region grouped into northern, central and southern England). Ethnicity was not included because data were not available before 2013.

Smoking characteristics assessed were: number of cigarettes smoked per day, daily vs. non-daily smoking, time to first cigarette (within 5 minutes vs. $\geq 6$ minutes) [18], strength of urges to smoke (an indicator of cigarette addiction) [19], motivation to stop smoking [20], whether the participant was currently cutting down, current use of e-cigarettes for any reason [21], current use of NRT, whether the participant had tried 
to quit in the last year, and inflation-adjusted weekly expenditure on smoking. While there is some debate as to whether e-cigarettes should be classified as a tobacco product alongside RYO and FM cigarettes [22], we chose not to include e-cigarette use as a third dependent variable on the basis that (i) e-cigarettes do not contain tobacco, (ii) e-cigarette use does not involve combustion and thus cannot be considered a form of smoking, and (iii) e-cigarettes are not classified as a tobacco product in England, where this study was conducted.

\section{Statistical analysis}

The analysis plan was pre-registered on OpenScienceFramework (https://osf.io/56t3b/).

Data were weighted to match the English population on age, sex, social grade and region. Missing data on sociodemographic and smoking characteristics were generally low, with complete data available for age, sex, social grade and non-daily smoking, and $<2 \%$ missing for region, cigarettes per day, time to first cigarette, and past-year quit attempts. A small number of smoking characteristics were not collected on every wave, and as such there were more missing data: current use of e-cigarettes (5.3\%), current use of NRT (5.3\%), cutting down (5.4\%), strength of urges to smoke (6.0\%), motivation to stop smoking (9.6\%) and weekly expenditure on smoking (15.5\%). Under the missing at random assumption, missing values were imputed (using SPSS v.24) using an imputation model with all other variables as predictors [23]. Five imputed datasets were created, each analysed separately, and the results combined to produce pooled estimates of effects; allowing the analyses to account for uncertainty caused by estimating missing data. Pooled estimates are reported throughout the paper.

We used descriptive statistics to analyse annual trends for (i) any, (ii) predominant and (iii) exclusive use of RYO and FM cigarettes among adults in England. We used logistic regression on aggregated data across the entire study period to examine the extent to which sociodemographic and smoking characteristics were associated with predominant use of RYO vs. predominant use of FM cigarettes in current smokers. Bivariate associations between predominant RYO cigarette use and each potential correlate were tested separately and independent associations were assessed with a multivariable model that included all variables. In addition, in order to examine whether profiles of RYO cigarette smokers have changed over time, we used data collected in 2008 and 2017 to test the $2 \times 2$ interaction between survey year (2008 vs. 2017) and type of cigarettes smoked (RYO vs. FM) for each sociodemographic and smoking-related characteristic. We used logistic regression for categorical outcomes and linear regression for continuous outcomes. We applied a 
false discovery rate correction [24] to all $p$-values using an online calculator (https://www.sdmproject.com/utilities/?show=FDR) to adjust for multiple comparisons.

We calculated Bayes factors (BF; planned a priori) for non-significant results in order to examine whether these associations could best be characterised as evidence of no effect or whether data were insensitive to detect an effect $[25,26]$. Alternative hypotheses were represented by half-normal distributions and the absolute expected effect size for categorical outcomes was set to $O R=3.0$ in the observed direction (i.e. $\mathrm{OR}=3.0$ for observed $\mathrm{ORs}>1$ and $\mathrm{OR}=0.33$ for observed $\mathrm{ORs}<1$ ) and for continuous outcomes was set to beta $=0.5$ (i.e. beta $=0.5$ for observed betas $>0$ and beta $=-0.5$ for observed betas $<0$ ) based on previous research into important differences in user characteristics between RYO and FM cigarette smokers $[10,11,11] . B F s \geq 3$ can be interpreted as evidence for the alternative hypothesis (and against the null), BFs $\leq 1 / 3$ as evidence for the null hypothesis, and BFs between $1 / 3$ and 3 suggest the data are insensitive to distinguish the alternative hypothesis from the null $[25,27]$.

All analyses were performed in SPSS v.24 with the exception of the Bayes factors which were calculated using an online calculator (http://www.lifesci.sussex.ac.uk/home/Zoltan_Dienes/inference/Bayes.htm).

\section{Results}

A total of 211,469 individuals responded to the survey between 2008 and 2017 (range 18,999-24,821 per year). Over the 10-year study period, the overall prevalence of cigarette smoking in the adult population in England fell from $22.0 \%$ to $17.2 \%$. There was a clear decline in use of FM cigarettes (Figure 1). In 2008, the prevalence of any, predominant and exclusive use of FM cigarettes was $16.4 \%, 15.3 \%$ and $14.3 \%$, respectively. In 2017, it was 9.7\%, 9.2\% and 8.8\% (a 40.9\%, 39.9\% and 38.5\% decrease), respectively. By contrast, RYO cigarette use increased (Figure 1). In 2008, the prevalence of any, predominant and exclusive use of RYO cigarettes was 7.7\%, 6.7\% and 5.6\%, respectively. In 2017, it was $8.4 \%, 8.1 \%$ and $7.5 \%$ (a 9.1\%, $20.9 \%$ and $33.9 \%$ increase), respectively. Among smokers who reported any use of RYO cigarettes in 2008 $(n=8,778), 72.8 \%$ reported exclusive use (i.e. RYO comprised $100 \%$ of their total cigarette consumption), $14.0 \%$ reported predominant but not exclusive use (50-99\% of their total cigarette consumption), and the remaining $13.1 \%$ reported non-predominant use (1-49\% of total cigarette consumption). In 2017 ( $n=10,276$ RYO users), the respective figures were $89.4 \%, 6.0 \%$, and $4.7 \%$. 
Associations in current smokers $(n=43,389)$ between predominant RYO cigarette use (vs. predominant FM cigarette use) and sociodemographic and smoking characteristics are shown in Table 1. Among current smokers, there were significant bivariate associations between predominant RYO cigarette use and all sociodemographic and smoking characteristics. In the multivariable model, there remained significant independent associations between predominant RYO cigarette use and younger age, male sex, lower social grade, region, a higher number of cigarettes per day, daily smoking, shorter time to first cigarette, stronger urges to smoke, lower motivation to stop, current e-cigarette use, non-use of NRT, and lower weekly spending on smoking. No significant independent association was detected between predominant RYO cigarette use and either currently cutting down or past-year quit attempts in the multivariable model.

The sociodemographic and smoking characteristics of predominant RYO and predominant FM cigarette smokers in $2008(n=4,183)$ and $2017(n=3,502)$ are summarised in Table 2 . There were significant interactions between survey year (2008 vs. 2017) and type of cigarettes smoked (RYO vs. FM) for age, sex, currently cutting down and past-year quit attempts. Between 2008 and 2017, relative to FM cigarette smokers, there was an increase in the proportion of RYO cigarette smokers who were younger and female and a smaller decrease in the proportion of RYO cigarette smokers who were currently cutting down or had made at least one serious quit attempt in the past year. The remaining interactions were not significant and further investigated by calculating Bayes factors (BF). These (see Supplementary Table) indicated strong evidence for the null hypothesis of no association between RYO cigarette use and currently cutting down and past-year quit attempts (BF 0.03). There was moderate to strong evidence for the null hypothesis for interactions between survey year and RYO cigarette use for cigarettes per day, non-daily smoking, strength of urges to smoke, high motivation to stop, current use of NRT, and weekly spending on smoking (BF range 0.06-0.32), but data were insensitive to detect interactions between survey year and RYO cigarette use for social grade, region, and time to first cigarette (BF range $0.37-0.47$ ).

\section{Discussion}

Between 2008 and 2017, the prevalence of FM cigarette smoking in adults in England fell by around 40\%. Predominant use of FM cigarettes declined from $15.3 \%$ to $9.2 \%$ and exclusive use declined from $14.3 \%$ to $8.8 \%$. By contrast, there was an increase in the prevalence of RYO cigarette smoking, with predominant use increasing by $20.9 \%$ (from $6.7 \%$ to $8.1 \%$ ) and exclusive use increasing by $33.9 \%$ (from $5.6 \%$ to $7.5 \%$ ). 
Across the entire 10-year study period, odds of RYO cigarette smoking were higher among younger, male smokers from lower social grades who lived in central and southern England. Odds of RYO use were also higher among smokers who smoked more cigarettes per day, were more addicted, and reported current use of e-cigarettes. However, odds of RYO use were lower among smokers who reported being a non-daily smoker, having high motivation to stop, current use of NRT, and higher weekly spending on smoking.

The profile of smokers who used RYO cigarettes was relatively stable over time, although the proportion who were younger and female increased between 2008 and 2017, over and above changes seen in smokers who used FM cigarettes. There was also a smaller decline in the proportion who were cutting down or had made a past-year quit attempt among RYO than FM smokers.

A trend for increasing use of RYO cigarettes in the context of a decline in overall smoking prevalence and use of FM cigarettes is in line with previous studies in the UK and other high-income countries $[10,11,13,14]$. It is likely these changes are driven by increases in the cost of smoking. Cost has been identified as the main reason smokers choose RYO over FM cigarettes [28] and is a leading motive for quitting [29]. With raising the cost of smoking identified as an effective means of reducing smoking [2-5], the UK government has implemented progressive tax increases which have resulted in cigarette prices rising to among the highest in Europe [30]. However, on average, RYO cigarettes are substantially cheaper than FM cigarettes [8] at approximately $£ 0.20$ (based on the UK mean of $0.48 \mathrm{~g}$ of tobacco per cigarette [31]) vs. $£ 0.53$ per cigarette [32,33], and a higher proportion are obtained illicitly [34]. This price gap is exacerbated by the tobacco industry differentially shifting tax increases between brand segments: while taxes on more expensive brands are consistently 'overshifted' with price rises on top of the tax increase, taxes on the cheapest products are not always fully passed onto consumers [8]. Thus, as the cost of smoking increases, some FM smokers will be encouraged to quit [2-7] but others may look to an alternate, cheaper product to mitigate the cost differential. Simultaneously, the existing cohort of RYO smokers would have been less likely to attempt to stop.

The plateau in prevalence of RYO cigarette use since 2015 may be attributable to the additional 3\% increase in the duty on RYO tobacco implemented in 2016 [1] narrowing the price gap between RYO and FM cigarettes in England. However, even among FM smokers, expenditure on smoking did not increase substantially between 2008 and 2017, indicating that there must be other strategies used to mitigate price increases, such as cutting down the number of cigarettes smoked, buying illicit cigarettes, and altering smoking behaviour to titrate nicotine intake $[35,36]$. 
Consistent with previous evidence that smokers who are younger and socioeconomically disadvantaged are most responsive to changes in price [5,7], we observed higher odds of RYO cigarette use among younger smokers and those from lower social grades. The association between younger age and RYO use is in contrast to the findings of previous studies which have found older people are more likely to use RYO cigarettes [11,12]. This discrepancy could reflect a change in the profile of smokers who use RYO cigarettes over time. Results from the present study and previous research indicate that RYO cigarette use is increasing considerably among younger smokers, with around three-quarters of young smokers opting for cheap tobacco products [10].

An association between socioeconomic disadvantage and RYO cigarette use has been consistently observed in previous studies using a range of indices, including income, financial stress, unemployment, occupation, and level of education $[10-12,15]$. We replicated the association between routine and manual occupations (indicated by lower social grade) and higher odds of RYO use, but did not have data available on other socioeconomic variables. Socioeconomic inequalities in smoking are well documented, with the most disadvantaged members of society substantially more likely to smoke and less likely to quit than the most affluent people $[37,38]$. However, evidence suggests this is not because they are less motivated to stop, make a quit attempt or use cessation support $[39,40]$, but could be due to higher levels of addiction making quitting more difficult [40]. By offering a means for smokers with low disposable incomes to offset rises in the cost of smoking, the lower cost of RYO cigarettes may exacerbate inequalities in smoking and its associated consequences for health. On a population level, the global financial crisis and recession that occurred during the study period disproportionately increased unemployment and reduced income for people from lower social grades. Well-documented stressors associated with rising income inequality may increase smoking and other forms of substance abuse regardless of pricing interventions [41,42].

We also observed higher prevalence of RYO cigarette use among men than women, in line with previous research $[10-12,15]$. However, the gender gap appeared to have narrowed over time. There was a significant increase in the proportion of RYO cigarette smokers who were female over the study period (from $38.3 \%$ in 2008 to $42.5 \%$ in 2017), and a small decline in the proportion of FM cigarette smokers who were female. There were also regional differences in the prevalence of RYO cigarette use, as was observed in the British General Household Survey [10]. We did not formally test differences in RYO use by ethnicity because this variable was not included in the Smoking Toolkit Study until 2013 and there were therefore a large number of missing values; however, in a subsample with available data, white ethnicity was associated with increased odds of RYO use (data not shown), consistent with previous findings [10]. 
In addition to sociodemographic differences, we observed substantial differences in the odds of RYO use according to a number of smoking characteristics. Associations between RYO use and heavier smoking and lower motivation to stop have previously been reported $[11,12,15]$. The present results confirm these associations and add to the descriptive picture of RYO smokers in England by identifying associations with other factors, including level of addiction and non-daily smoking. We found that people who smoked more heavily, were more addicted and reported current use of e-cigarettes had significantly higher odds of smoking RYO cigarettes, while those who reported having high motivation to stop, non-daily smoking and current use of NRT had significantly lower odds. The associations with current use of NRT and e-cigarettes likely reflect the declining overall use of NRT during this period that RYO became more popular, while the use of e-cigarettes followed the opposite pattern.

Across the entire study period, there was no evidence of an association between attempts to quit or cut down and use of RYO cigarettes after adjustment for other sociodemographic and smoking characteristics. This finding is in line with our previous study that found there was no significant association between RYO cigarette use and quit attempts when the lower cost of smoking RYO relative to FM cigarettes was controlled for [9]. However, the change in prevalence of past-year quit attempts and cutting down between 2008 and 2017 differed significantly between smokers of RYO and FM cigarettes. Compared with FM cigarette smokers, there was a significantly smaller decline in the proportion of RYO cigarette smokers who reported a past-year quit attempt or trying to cut down their cigarette consumption. This resulted in the two groups of smokers becoming more similar over time: quit attempts and cutting down were more frequently reported by FM cigarette smokers than RYO cigarette smokers in 2008, but there was little difference in prevalence in 2017.

A major strength of this study was the large, representative sample. However, there were also limitations. Quit attempts were self-reported and relied on recall of the past year, introducing scope for bias. Expenditure on smoking was estimated based on recall of average weekly spend, and may have been less accurate for RYO smokers than FM smokers. Items on cutting down and current use of NRT and e-cigarettes were not included in every wave, so we imputed missing values. Sensitivity analysis using Bayes factors indicated that for non-significant associations and interactions, the data generally favoured the null hypothesis but were insensitive to detect changes in the distribution of social grades, regions and level of cigarette addiction among RYO cigarette smokers between 2008 and 2017, so it is possible there were small changes in these characteristics that were not detected in this study. 
These results show that the prevalence of RYO cigarette use in England has increased over the past decade despite an overall reduction in smoking prevalence and use of FM cigarettes. This pattern is likely being driven by differential tax increases on RYO vs. FM cigarettes, with RYO offering a more affordable option. As such, the clearest policy intervention for RYO use relates to tax. Smokers who use RYO cigarettes are typically younger, male, and more socioeconomically disadvantaged than those who use FM cigarettes. They smoke more heavily, are more addicted to cigarettes, spend less on smoking, and are less inclined to quit. As such, targeting interventions or tobacco control policies at young, male, and disadvantaged smokers may help to stem the continued use of tobacco (especially RYO) among these priority groups. 


\section{References}

1 Department of Health. Towards a Smokefree Generation: A Tobacco Control Plan for England. London: : Department of Health 2017.

https://assets.publishing.service.gov.uk/government/uploads/system/uploads/attachment_data/file/6 30217/Towards_a_Smoke_free_Generation_-_A_Tobacco_Control_Plan_for_England_2017-

2022_2_.pdf (accessed 13 Sep 2018).

2 Jha P, Peto R. Global Effects of Smoking, of Quitting, and of Taxing Tobacco.

http://dx.doi.org/10.1056/NEJMra1308383. 2014. doi:10.1056/NEJMra1308383

3 IARC. IARC Handbooks of Cancer Prevention: Tobacco Control. Volume 14. Effectiveness of Price and Tax Policies for Control of Tobacco. Lyon, France: : International Agency for Research on Cancer 2011.

4 World Health Organization. Guidelines for implementation of Article 6 of the WHO FCTC: Price and tax measures to reduce the demand for tobacco.

2011.http://www.who.int/fctc/guidelines/adopted/Guidelines_article_6.pdf?ua=1 (accessed 16 May 2018).

5 Mayne SL, Gordon-Larsen P, Schreiner PJ, et al. Longitudinal Associations of Cigarette Prices with Smoking Cessation: the Coronary Artery Risk Development in Young Adults (CARDIA) Study. Nicotine Tob Res Published Online First: 2018. doi:10.1093/ntr/nty109

6 Gallus S, Schiaffino A, Vecchia CL, et al. Price and cigarette consumption in Europe. Tob Control 2006;15:114-9. doi:10.1136/tc.2005.012468

7 Chaloupka FJ, Straif K, Leon ME, et al. Effectiveness of tax and price policies in tobacco control. Tob Control 2011;20:235-8. doi:10.1136/tc.2010.039982

8 Gilmore AB, Tavakoly B, Taylor G, et al. Understanding tobacco industry pricing strategy and whether it undermines tobacco tax policy: the example of the UK cigarette market. Addiction 2013;108:1317-26. doi:10.1111/add.12159

9 Jackson SE, Shahab L, West R, et al. Roll-your-own cigarette use and smoking cessation behaviour: a population study. BMJ Open revised manuscript under review.

10 Gilmore AB, Tavakoly B, Hiscock R, et al. Smoking patterns in Great Britain: the rise of cheap cigarette brands and roll your own (RYO) tobacco. J Public Health 2015;37:78-88. doi:10.1093/pubmed/fdu048

11 Young $\mathrm{D}$, Yong $\mathrm{H}-\mathrm{H}$, Borland R, et al. Trends in Roll-Your-Own Smoking: Findings from the ITC FourCountry Survey (2002-2008). J. Environ. Public Health. 2012.https://www.hindawi.com/journals/jeph/2012/406283/ (accessed 24 May 2018).

12 Brown AK, Nagelhout GE, Putte B van den, et al. Trends and socioeconomic differences in roll-your-own tobacco use: findings from the ITC Europe Surveys. Tob Control 2015;24:iii11-6.

doi:10.1136/tobaccocontrol-2014-051986 
13 Partos TR, Gilmore AB, Hitchman SC, et al. Availability and Use of Cheap Tobacco in the United Kingdom 2002-2014: Findings From the International Tobacco Control Project. Nicotine Tob Res Off J Soc Res Nicotine Tob 2018;20:714-24. doi:10.1093/ntr/ntx108

14 Rothwell L, Britton J, Bogdanovica I. The relation between cigarette price and hand-rolling tobacco consumption in the UK: an ecological study. BMJ Open 2015;5:e007697. doi:10.1136/bmjopen-2015007697

15 Young D, Borland R, Hammond D, et al. Prevalence and attributes of roll-your-own smokers in the International Tobacco Control (ITC) Four Country Survey. Tob Control 2006;15:iii76-82. doi:10.1136/tc.2005.013268

16 Fidler JA, Shahab L, West O, et al. "The smoking toolkit study": a national study of smoking and smoking cessation in England. BMC Public Health 2011;11:479. doi:10.1186/1471-2458-11-479

17 National Readership Survey. Social grade - definitions and discriminatory power. 2007.http:// www.nrs.co.uk/lifestyle.html (accessed 1 Oct 2012).

18 Heatherton TF, Kozlowski LT, Frecker RC, et al. The Fagerström test for nicotine dependence: a revision of the Fagerstrom Tolerance Questionnaire. Br J Addict 1991;86:1119-1127.

19 Fidler JA, Shahab L, West R. Strength of urges to smoke as a measure of severity of cigarette dependence: comparison with the Fagerström Test for Nicotine Dependence and its components. Addict Abingdon Engl 2011;106:631-8. doi:10.1111/j.1360-0443.2010.03226.x

20 Kotz D, Brown J, West R. Predictive validity of the Motivation To Stop Scale (MTSS): A single-item measure of motivation to stop smoking. Drug Alcohol Depend 2013;128:15-9. doi:10.1016/j.drugalcdep.2012.07.012

21 Beard E, West R, Michie S, et al. Association between electronic cigarette use and changes in quit attempts, success of quit attempts, use of smoking cessation pharmacotherapy, and use of stop smoking services in England: time series analysis of population trends. BMJ 2016;354:i4645. doi:10.1136/bmj.i4645

22 Munafo M. Are e-Cigarettes Tobacco Products? Nicotine Tob Res 2019;21:267-267. doi:10.1093/ntr/nty130

23 Pedersen AB, Mikkelsen EM, Cronin-Fenton D, et al. Missing data and multiple imputation in clinical epidemiological research. Clin Epidemiol 2017;9:157-66. doi:10.2147/CLEP.S129785

24 Benjamini Y, Hochberg Y. Controlling the false discovery rate: a practical and powerful approach to multiple testing. J R Stat Soc Ser B Methodol 1995;:289-300.

25 Dienes Z. Using Bayes to get the most out of non-significant results. Front Psychol 2014;5. doi:10.3389/fpsyg.2014.00781

26 West R. Using Bayesian analysis for hypothesis testing in addiction science. Addiction 2015;111:3-4. doi:10.1111/add.13053 
27 Jeffreys H. The Theory of Probability. Oxford: : Clarendon Press 1961.

28 Joseph S, Krebs NM, Zhu J, et al. Differences in nicotine dependence, smoke exposure and consumer characteristics between smokers of machine-injected roll-your-own cigarettes and factory-made cigarettes. Drug Alcohol Depend 2018;187:109-15. doi:10.1016/j.drugalcdep.2018.01.039

29 McCaul KD, Hockemeyer JR, Johnson RJ, et al. Motivation to quit using cigarettes: A review. Addict Behav 2006;31:42-56. doi:10.1016/j.addbeh.2005.04.004

30 Bogdanovica I, Murray R, McNeill A, et al. Cigarette price, affordability and smoking prevalence in the European Union. Addict Abingdon Eng/ 2012;107:188-96. doi:10.1111/j.1360-0443.2011.03588.x

31 Gallus S, Lugo A, Ghislandi S, et al. ROLL-YOUR-OWN CIGARETTES IN EUROPE: USE, WEIGHT AND IMPLICATIONS FOR FISCAL POLICIES. Eur J Cancer Prev Off J Eur Cancer Prev Organ ECP 2014;23:186-92. doi:10.1097/CEJ.0000000000000010

32 RPI: Ave price - Cigarettes 20 king size filter - Office for National Statistics. https://www.ons.gov.uk/economy/inflationandpriceindices/timeseries/czmp (accessed 3 Feb 2019).

33 Hand rolling tobacco prices across Europe 2016 | UK Statistic. Statista. https://www.statista.com/statistics/415091/hand-rolling-tobacco-prices-across-europe/ (accessed 3 Feb 2019).

34 Rowell A, Evans-Reeves K, Gilmore AB. Tobacco industry manipulation of data on and press coverage of the illicit tobacco trade in the UK. Tob Control 2014;23:e35-43. doi:10.1136/tobaccocontrol-2013051397

35 Jarvis MJ, Boreham R, Primatesta P, et al. Nicotine Yield From Machine-Smoked Cigarettes and Nicotine Intakes in Smokers: Evidence From a Representative Population Survey. JNCl J Nat/ Cancer Inst 2001;93:134-8. doi:10.1093/jnci/93.2.134

36 Joossens L, Raw M. From cigarette smuggling to illicit tobacco trade. Tob Control 2012;21:230-4. doi:10.1136/tobaccocontrol-2011-050205

37 Jarvis $\mathrm{M}$, Wardle J. Social patterning of individual health behaviours: the case of cigarette smoking. In: Social Determinants of Health. Oxford: : Oxford University Press 2003. 22537.http://www.oxfordscholarship.com/view/10.1093/acprof:oso/9780198565895.001.0001/acprof9780198565895-chapter-11 (accessed 18 Jul 2018).

38 Hiscock R, Bauld L, Amos A, et al. Smoking and socioeconomic status in England: the rise of the never smoker and the disadvantaged smoker. J Public Health Oxf Eng/ 2012;34:390-6.

doi:10.1093/pubmed/fds012

39 Kotz D, West R. Explaining the social gradient in smoking cessation: it's not in the trying, but in the succeeding. Tob Control 2009;18:43-6. doi:10.1136/tc.2008.025981

40 Jackson SE, Smith C, Cheeseman H, et al. Finding smoking hotspots: a cross sectional survey of smoking patterns by housing tenure in England. Addiction revisions under review. 
41 Siahpush M, Borland R, Taylor J, et al. The association of smoking with perception of income inequality, relative material well-being, and social capital. Soc Sci Med 2006;63:2801-12. doi:10.1016/j.socscimed.2006.07.015

42 Pickett KE, Wilkinson RG. Income inequality and health: A causal review. Soc Sci Med 2015;128:316-26. doi:10.1016/j.socscimed.2014.12.031 


\section{Declarations}

\section{Ethics approval and consent to participate}

Ethical approval for the Smoking Toolkit Study was granted originally by the UCL Ethics Committee (ID 0498/001) and participants provided full informed consent. The data are not collected by UCL and are anonymised when received by UCL.

\section{Availability of data and materials}

The datasets used and/or analysed during the current study are available from the corresponding author on reasonable request.

\section{Competing interests}

JB received unrestricted research funding from Pfizer, who manufacture smoking cessation medications. LS has received honoraria for talks, an unrestricted research grant and travel expenses to attend meetings and workshops from Pfizer, and has acted as paid reviewer for grant awarding bodies and as a paid consultant for health care companies. RW undertakes research and consultancy for and receives travel funds and hospitality from manufacturers of smoking cessation medications (Pfizer, GlaxoSmithKline and Johnson and Johnson). All authors declare no financial links with tobacco companies or e-cigarette manufacturers or their representatives.

\section{Funding}

Cancer Research UK funded data collection (C1417/A22962; C44576/A19501) and SJ, CG \& JB's salary (C1417/A22962). The funders had no final role in the study design; in the collection, analysis and interpretation of data; in the writing of the report; or in the decision to submit the paper for publication. All researchers listed as authors are independent from the funders and all final decisions about the research were taken by the investigators and were unrestricted. 
Table 1 Bivariate and multivariable logistic regression models of associations with predominant roll-your-own cigarette use among current smokers

\begin{tabular}{|c|c|c|c|c|c|}
\hline & \multirow[b]{2}{*}{$\%^{\mathrm{a}}$} & \multicolumn{2}{|l|}{ Bivariate } & \multicolumn{2}{|c|}{ Multivariable } \\
\hline & & OR [95\% Cl] & $p^{\mathrm{b}}$ & OR [95\% Cl] & $p^{b}$ \\
\hline \multicolumn{6}{|l|}{ Age in years } \\
\hline $16-24$ & 43.8 & 1.00 & - & 1.00 & - \\
\hline $25-34$ & 38.3 & $0.80[0.75-0.85]$ & $<0.001$ & $0.85[0.79-0.92]$ & $<0.001$ \\
\hline $35-44$ & 39.6 & $0.84[0.79-0.90]$ & $<0.001$ & $0.89[0.82-0.96]$ & 0.005 \\
\hline $45-54$ & 40.4 & $0.87[0.82-0.93]$ & $<0.001$ & $0.88[0.81-0.96]$ & 0.004 \\
\hline $55-64$ & 36.6 & $0.74[0.69-0.80]$ & $<0.001$ & $0.74[0.67-0.81]$ & $<0.001$ \\
\hline$\geq 65$ & 26.9 & $0.47[0.44-0.51]$ & $<0.001$ & $0.47[0.42-0.52]$ & $<0.001$ \\
\hline \multicolumn{6}{|l|}{ Sex } \\
\hline Women & 31.6 & 1.00 & - & 1.00 & - \\
\hline Men & 45.1 & $1.78[1.71-1.85]$ & $<0.001$ & 1.86 [1.77-1.95] & $<0.001$ \\
\hline \multicolumn{6}{|l|}{ Social grade } \\
\hline $\mathrm{ABC1}$ & 32.6 & 1.00 & - & 1.00 & - \\
\hline C2DE & 42.6 & $1.54[1.48-1.60]$ & $<0.001$ & $1.31[1.24-1.37]$ & $<0.001$ \\
\hline \multicolumn{6}{|l|}{ Region } \\
\hline North & 35.4 & 1.00 & - & 1.00 & - \\
\hline Central & 39.6 & $1.20[1.14-1.26]$ & $<0.001$ & $1.28[1.20-1.36]$ & $<0.001$ \\
\hline South & 40.9 & $1.27[1.21-1.33]$ & $<0.001$ & $1.36[1.28-1.44]$ & $<0.001$ \\
\hline \multicolumn{6}{|l|}{ Non-daily smoker } \\
\hline No & 39.8 & 1.00 & - & 1.00 & - \\
\hline Yes & 29.6 & $0.63[0.59-0.68]$ & $<0.001$ & $0.46[0.43-0.50]$ & $<0.001$ \\
\hline \multicolumn{6}{|l|}{ Time to first cigarette } \\
\hline 6 or more minutes & 37.0 & 1.00 & - & 1.00 & - \\
\hline Within 5 minutes & 46.3 & $1.47[1.40-1.55]$ & $<0.001$ & $1.49[1.38-1.60]$ & $<0.001$ \\
\hline \multicolumn{6}{|l|}{ High motivation to stop ${ }^{d}$} \\
\hline No & 40.0 & 1.00 & - & 1.00 & - \\
\hline Yes & 33.1 & $0.74[0.70-0.79]$ & $<0.001$ & $0.84[0.79-0.90]$ & $<0.001$ \\
\hline \multicolumn{6}{|l|}{ Currently cutting down } \\
\hline No & 40.7 & 1.00 & - & 1.00 & - \\
\hline Yes & 36.8 & $0.85[0.81-0.88]$ & $<0.001$ & $1.00[0.95-1.05]$ & 0.940 \\
\hline \multicolumn{6}{|c|}{ Current use of e-cigarette } \\
\hline No & 38.2 & 1.00 & - & 1.00 & - \\
\hline Yes & 42.9 & $1.22[1.14-1.30]$ & $<0.001$ & $1.64[1.51-1.79]$ & $<0.001$ \\
\hline \multicolumn{6}{|l|}{ Current use of NRT } \\
\hline No & 39.6 & 1.00 & - & 1.00 & - \\
\hline Yes & 33.2 & $0.76[0.72-0.80]$ & $<0.001$ & $0.87[0.81-0.94]$ & 0.001 \\
\hline \multicolumn{6}{|l|}{ Tried to quit in past year } \\
\hline No & 39.6 & 1.00 & - & 1.00 & - \\
\hline \multirow[t]{2}{*}{ Yes } & 36.6 & $0.88[0.84-0.92]$ & $<0.001$ & $0.99[0.93-1.05]$ & 0.737 \\
\hline & mean $[S D]^{c}$ & & & & \\
\hline Cigarettes per day & $12.66(8.68)$ & $1.01[1.01-1.02]$ & $<0.001$ & $1.13[1.12-1.14]$ & $<0.001$ \\
\hline
\end{tabular}




\begin{tabular}{lccccc}
\hline Strength of urges to smoke & $2.06(1.07)$ & $1.09[1.07-1.12]$ & $<0.001$ & $1.18[1.15-1.21]$ & $<0.001$ \\
\hline $\begin{array}{l}\text { Weekly spending on smoking } \\
\text { (f) }\end{array}$ & $15.48(12.44)$ & $0.94[0.94-0.94]$ & $<0.001$ & $0.89[0.89-0.89]$ & $<0.001$ \\
\hline a & & & & \\
\hline
\end{tabular}

a Percentage of current smokers in each category who reported predominant ( $\geq 50 \%)$ RYO cigarette use.

${ }^{\mathrm{b}} p$ values with false discovery rate correction applied.

c Mean [SD] for the group of current smokers who reported predominant RYO use.

d Defined as really wanting to stop smoking within the next three months.

e Self-rated strength of urges to smoke over the past 24 hours, on a scale from 0 (not at all) to 5 (extremely strong).

$\mathrm{OR}=$ odds ratio; $\mathrm{Cl}$ = confidence interval; $\mathrm{SD}$ = standard deviation; $\mathrm{NRT}$ = nicotine replacement therapy. 
Table 2 Sociodemographic and smoking profile of roll-your-own vs. factory-made cigarette smokers in England: 2008 and 2017

\begin{tabular}{|c|c|c|c|c|c|c|c|c|}
\hline & \multicolumn{3}{|c|}{ RYO cigarette smokers $^{\mathrm{a}}$} & \multicolumn{3}{|c|}{ FM cigarette smokers ${ }^{\mathrm{b}}$} & \multicolumn{2}{|c|}{ Interaction $^{\mathrm{c}}$} \\
\hline & 2008 & 2017 & Change $^{d}$ & 2008 & 2017 & Change $^{d}$ & OR/Beta $[95 \% \mathrm{Cl}]$ & $p^{\mathrm{e}}$ \\
\hline Age in years (\%) & & & & & & & $0.63[0.53 ; 0.74]$ & $<0.001$ \\
\hline $16-24$ & 19.6 & 23.4 & 3.8 & 21.4 & 13.9 & -7.5 & - & - \\
\hline $25-34$ & 20.9 & 22.7 & 1.8 & 20.6 & 23.0 & 2.4 & - & - \\
\hline $35-44$ & 24.6 & 17.9 & -6.7 & 21.3 & 17.0 & -4.3 & - & - \\
\hline $45-54$ & 19.4 & 17.0 & -2.4 & 15.1 & 20.2 & 5.1 & - & - \\
\hline $55-64$ & 10.9 & 11.8 & 0.9 & 11.5 & 12.9 & 1.4 & - & - \\
\hline$\geq 65$ & 4.4 & 7.3 & 2.9 & 10.2 & 12.9 & 2.7 & - & - \\
\hline Women (\%) & 38.3 & 42.5 & 4.2 & 54.4 & 52.9 & -1.5 & $1.27[1.05 ; 1.53]$ & 0.019 \\
\hline Social grade C2DE (\%) & 69.9 & 66.4 & -3.5 & 57.8 & 57.7 & -0.1 & $0.86[0.70 ; 1.04]$ & 0.152 \\
\hline Region (\%) & & & & & & & $0.87[0.73 ; 1.03]$ & 0.131 \\
\hline North & 28.7 & 30.5 & 1.8 & 38.3 & 32.7 & -5.6 & - & - \\
\hline Central & 35.7 & 28.1 & -7.6 & 29.5 & 30.4 & 0.9 & - & - \\
\hline South & 35.6 & 41.4 & 5.3 & 32.2 & 36.8 & 4.6 & - & - \\
\hline Cigarettes per day (mean [SD]) & $14.08(9.03)$ & $11.10(8.34)$ & $-2.97(0.33)$ & $13.15(8.53)$ & $10.45(7.92)$ & $-2.69(0.24)$ & $-0.01[-0.05 ; 0.03]$ & 0.525 \\
\hline Non-daily smoker (\%) & 6.7 & 12.2 & 5.5 & 10.7 & 15.8 & 5.1 & $1.24[0.91 ; 1.70]$ & 0.211 \\
\hline First cigarette within 5 min of waking (\%) & 27.0 & 16.3 & -10.7 & 18.1 & 11.9 & -6.2 & $0.86[0.67 ; 1.11]$ & 0.283 \\
\hline Strength of urges to smoke $(\text { mean }[S D])^{f}$ & $2.13(1.06)$ & $1.89(1.07)$ & $-0.24(0.04)$ & $2.07(1.01)$ & $1.80(1.12)$ & $-0.28(0.03)$ & $0.02[-0.03 ; 0.06]$ & 0.489 \\
\hline High motivation to stop (\%)g & 19.0 & 14.8 & -4.2 & 25.4 & 16.9 & -8.5 & $1.24[0.90 ; 1.72]$ & 0.212 \\
\hline Currently cutting down (\%) & 50.6 & 46.7 & -3.9 & 58.3 & 47.5 & -10.8 & $1.33[1.10 ; 1.60]$ & 0.004 \\
\hline Currently using e-cigarette $(\%)^{d}$ & 0.0 & 19.9 & 19.9 & 0.0 & 17.3 & 17.3 & - & - \\
\hline Currently using NRT (\%) & 14.4 & 8.5 & -5.9 & 18.2 & 10.4 & -7.8 & $1.05[0.78 ; 1.41]$ & 0.754 \\
\hline Tried to quit in past year (\%) & 32.9 & 30.4 & -2.5 & 38.7 & 29.2 & -9.5 & $1.36[1.11 ; 1.67]$ & 0.004 \\
\hline Weekly spending on smoking (mean [SD] f) & $15.01(11.75)$ & $15.37(11.70)$ & $0.36(0.44)$ & $30.20(18.40)$ & 30.86 (19.67) & $0.66(0.57)$ & $-0.01[-0.04 ; 0.03]$ & 0.739 \\
\hline $\begin{array}{l}\text { a Descriptive characteristics of roll-your-own smok } \\
\text { b Descriptive characteristics of factory-made smok } \\
\text { c The } 2 \times 2 \text { interaction between survey year ( } 2008 \mathrm{~V} \\
\text { mean (SE) change between } 2008 \text { and } 2017 \text {. } \\
\text { e } p \text { values with false discovery rate correction app } \\
\text { f Self-rated strength of urges to smoke over the pa } \\
\text { g Defined as really wanting to stop smoking within } \\
\text { f It was not possible to compute an interaction ter }\end{array}$ & $\begin{array}{l}\text { s responding to } \\
\text { s responding to } \\
\text { 2017) and type c } \\
\text { d. } \\
24 \text { hours, on a s } \\
\text { e next three mo } \\
\text { for current use c }\end{array}$ & $\begin{array}{l}\text { Smoking Toolkit } \\
\text { Smoking Toolkit } \\
\text { igarettes smokec } \\
\text { from } 0 \text { (not at } \\
\text { s. }\end{array}$ & $\begin{array}{l}\text { udy surveys in } \\
\text { udy surveys in } \\
\text { oll-your-own v } \\
\text { to } 5 \text { (extremel }\end{array}$ & $\begin{array}{l}\text { and } 2017 \text { (aggre } \\
\text { and } 2017 \text { (aggre } \\
\text { ory-made) for e } \\
\text { gg). }\end{array}$ & $\begin{array}{l}\text { ted monthly da } \\
\text { ted monthly da } \\
\text { h sociodemogra }\end{array}$ & and smoking & ated characteristic. ${ }^{\mathrm{d}} \mathrm{F}$ & rcent or \\
\hline
\end{tabular}


